\title{
Experts question timing of vaccination against shingles
}

$\mathrm{M}$ erck Canada's advertising campaign that pitches its vaccine against shingles to people aged 50 and over is running afoul of vaccinologists, who caution it might be better administered at age 60 .

"We know for sure that protection lasts about five years, but if we vaccinate early, there's a chance that people may not still be protected by the time they are at highest risk of getting shingles," says Dr. Shelly McNeil, a clinician scientist at the Canadian Center for Vaccinology in Halifax, Nova Scotia.

In national television and magazine ads, Merck has been urging people aged 50 and over to get protected against herpes zoster (shingles) by being vaccinated with Zostavax. "It is estimated that nearly one in 3 people will experience shingles in their lifetime. And that risk increases after the age of 50. Will you be the one?" Merck's advertising campaign asks.

But Zostavax's protection against shingles is not indefinite. Merck began a 10-year effectiveness study in 2008, so it does not yet know if protection from a single dose of the vaccine lasts beyond seven years, says Sheila Murphy, a spokesperson for Merck.

"If you get the vaccine you'll be protected," says Dr. Deepali Kumar, an associate professor of medicine in transplant infectious diseases at the University of Alberta and a member of the National Advisory Committee on Immunization (NACI). "But whether you'll need another booster 10 years later is not known."

This uncertainty can be expensive. The vaccine is not covered under provincial or territorial vaccination programs and costs $\$ 153.15$ (list price). If an adult was vaccinated at 50 , but needed a booster every seven years until age 78 , for example, it would cost about $\$ 612$.

Herpes zoster is caused by the reactivation of the varicella zoster virus, the culprit behind chicken pox and a virus that lies latent in nerve roots around the spinal cords of $95 \%$ of Canadians. Age decreases natural immunity to the zoster virus, as do immunosuppressive drugs. When the virus returns, it does so as

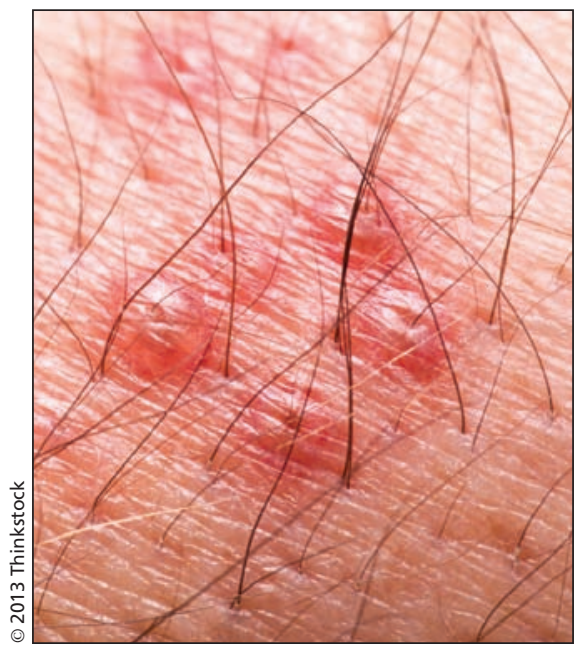

The risk of experiencing shingles, which causes a painful rash and lingering discomfort, increases with age.

shingles, a painful rash often accompanied by severe discomfort even months after the rash subsides.

A study on the cost-effectiveness of vaccination against herpes zoster (Human Vaccines 2008;4: 238-45) concluded that vaccinating adults between the ages of 65 and 75 years would likely be the most cost-effective.

There are an estimated 130000 new cases of herpes zoster virus in Canada each year, most in adults aged 60 and older, according to the Human Vaccines study. The US Centers for Disease Control and Prevention reports that about $50 \%$ of people who live to age 85 will have an episode of shingles.

NACI recommends all adults over 60 receive one dose of Zostavax. The risk of shingles for people under age 60 is generally low, says McNeil, but it does begin to increase after age 60 . The incidence rises to 11 per 1000 in populations over age 80 , from 7 per 1000 in populations 60-69 years (Journal of the Royal College of General Practice, 1975:15;571-5).

When asked why Merck was targeting the vaccine at 50-year-olds and not those aged 60 and older - the population studied in a large clinical trial - the company pointed to the increased incidence and severity of herpes zoster after 50 .

"This means that the risk of shingles is greater every year," says Murphy. "As you have seen from the data, the vaccine is less effective as you get older," she added in an email to CMAJ.

Before Zostavax was approved for use in Canada in August 2008, there was no vaccination for shingles. The vaccine is $51 \%$ effective at preventing the illness in adults 60 years of age and older, and is the best preventive option we have right now, says McNeil.

The paradox of the vaccine's effectiveness decreasing with a patient's age does make the timing of the vaccination an issue, says Kumar.

"Since we don't have information on how long the vaccine will last, it's difficult to know at what age it makes most sense to get the Zostavax vaccination, where you're best able to balance its effectiveness against its cost," she says.

Merck's research suggests Zostavax's protective effect for people aged 60-69 is $63.9 \%$. For those aged 70, it is $37.6 \%$.

There is no reason not to publicly fund Zostavax, says McNeil.

As of April 2013, Merck says it had distributed 561439 doses of Zostavax in Canada.

Ironically, because Zostavax is a live attenuated vaccine, the very patients most at risk of getting shingles cannot take it. The vaccine is contraindicated for patients whose immune systems are compromised by immunosuppressive drugs.

NACI is reviewing the data on the use of shingles vaccine in those who are immunocompromised and hopes to provide evidence-based recommendations for that population in the next few months. Meanwhile, the Canadian Center for Vaccinology is participating in ongoing trials of new, inactivated or non-live vaccines in patients with hematologic and solid tumour malignancies and transplants. The results will not be available for several years, McNeil said.

The Canadian Immunization Committee, a task group of experts that provides recommendations for the use of a vaccine in publicly funded programs, is still developing its recommendations about funding Zostavax. - Lauren Kramer, Vancouver, BC

CMAJ 2013. DOI:10.1503/cmaj.109-4502 